\title{
A phase IIa randomized controlled pilot study evaluating the safety and clinical outcomes following the use of $\mathrm{rhGDF}-5 / \beta-\mathrm{TCP}$ in regenerative periodontal therapy
}

\author{
Péter Windisch • Andreas Stavropoulos • Bálint Molnár • Dóra Szendröi-Kiss • \\ Emese Szilágyi • Péter Rosta • Attila Horváth • Björn Capsius • Ulf M. E. Wikesjö • \\ Anton Sculean
}

Received: 29 August 2010 / Accepted: 10 August 2011 /Published online: 2 September 2011

(C) Springer-Verlag 2011

\begin{abstract}
To present the safety profile, the early healing phase and the clinical outcomes at 24 weeks following treatment of human intrabony defects with open flap debridement (OFD) alone or with OFD and rhGDF-5 adsorbed onto a particulate $\beta$-tricalcium phosphate $(\beta$ TCP) carrier. Twenty chronic periodontitis patients, each with at least one tooth exhibiting a probing depth $\geq 6 \mathrm{~mm}$ and an associated intrabony defect $\geq 4 \mathrm{~mm}$ entered the
\end{abstract}

P. Windisch $\cdot$ B. Molnár $\cdot$ D. Szendröi-Kiss $\cdot$ E. Szilágyi •

P. Rosta $\cdot$ A. Horváth

Department of Periodontology, Semmelweis University,

Budapest, Hungary

\section{A. Stavropoulos}

Department of Periodontology, School of Dentistry,

University of Aarhus,

Aarhus, Denmark

\author{
A. Stavropoulos \\ Center for Experimental and Preclinical Research (CEPBR), \\ Athens, Greece \\ B. Capsius \\ Scil Technology GmbH, \\ Martinsried, Germany \\ U. M. E. Wikesjö \\ Laboratory for Applied Periodontal \& Craniofacial Regeneration \\ (LAPCR), Departments of Periodontics and Oral Biology, \\ Medical College of Georgia School of Dentistry and School of \\ Graduate Studies, \\ Augusta, GA, USA \\ A. Sculean $(\bowtie)$ \\ Department of Periodontology, University of Bern, \\ Freiburgstrasse 7, \\ 3010 Bern, Switzerland \\ e-mail: anton.sculean@zmk.unibe.ch
}

study. Ten subjects (one defect/patient) were randomized to receive OFD alone (control) and ten subjects OFD combined with rhGDF-5/ $\beta$-TCP. Blood samples were collected at screening, and at weeks 2 and 24 to evaluate routine hematology and clinical chemistry, rhGDF-5 plasma levels, and antirhGDF-5 antibody formation. Plaque and gingival indices, bleeding on probing, probing depth, clinical attachment level, and radiographs were recorded pre- and 24 weeks postsurgery. Comparable safety profiles were found in the two treatment groups. Neither antirhGDF-5 antibody formation nor relevant rhGDF-5 plasma levels were detected in any patient. At 6 months, treatment with $\mathrm{OFD}+$ rhGDF-5/ $\beta$-TCP resulted in higher but statistically not significant PD reduction $(3.7 \pm 1.2$ vs. $3.1 \pm 1.8 \mathrm{~mm} ; p=0.26)$ and CAL gain $(3.2 \pm 1.7$ vs. $1.7 \pm$ $2.2 \mathrm{~mm} ; p=0.14)$ compared to OFD alone. In the tested concentration, the use of rhGDF-5/ $\beta$-TCP appeared to be safe and the material possesses a sound biological rationale. Thus, further adequately powered, randomized controlled clinical trials are warranted to confirm the clinical relevance of this new approach in regenerative periodontal therapy. rhGDF- $5 / \beta$-TCP may represent a promising new techology in regenerative periodontal therapy.

Keywords rhGDF-5 - Tissue engineering $\cdot$ Periodontal regeneration $\cdot$ Clinical trial $\cdot \beta$-TCP $\cdot$ Periodontal surgery

\section{Introduction}

Ultimately, periodontal regeneration aims at completely restoring the periodontal attachment lost due to disease or trauma including root cementum, periodontal ligament and alveolar bone [1]. Recent studies using controlled preclin- 
ical models provide ample biologic evidence suggesting that surgical protocols meeting critical requirements of space provision, wound stabilization, and conditions favoring primary intention healing may indeed support the reconstruction or regeneration of lost periodontal tissues [2, 3].

The 1996 American Academy of Periodontology World Workshop [4] formulated the following criteria for a treatment modality to be considered a periodontal regenerative procedure: 1) controlled histological animal studies demonstrating formation of new cementum, periodontal ligament, and alveolar bone; 2) controlled clinical studies demonstrating gain of clinical attachment and alveolar bone; and 3) human biopsies demonstrating formation of new cementum, periodontal ligament, and alveolar bone onto a previously "plaque-infected root surface". Fulfilling the first criterion, preclinical studies have pointed to a role of growth/differentiation factor (GDF) $-5,-6$, and -7 in the formation of the periodontal ligament $[5,6]$. Recombinant human GDF-5 (rhGDF-5) exhibits osteoinductive properties in vitro and in vivo [7]. Moreover, rhGDF-5 may provide an environment conducive to periodontal wound healing/regeneration affecting extracellular matrix metabolism [8]. Still other studies have shown significant periodontal regeneration in discriminating large animal models following surgical implantation of both GDF-5 and GDF-7 [9-11].

An rhGDF-5/ $\beta$-TCP device has been shown to enhance periodontal regeneration in deep one-wall intrabony defects in dogs [11]. The $\beta$-TCP carrier matrix exhibits a resorption profile that apparently minimally interferes with bone formation/remodeling and periodontal regeneration; $\beta$ TCP, being biocompatible, resorbs and is replaced by bone within weeks of implantation. Indeed, standalone $\beta$-TCP technologies have been used for orthopedic and craniofacial indications for more than 20 years as implantable bone substitutes [12]. A recent study has shown that rhGDF-5/ $\beta$ TCP implanted in a rat calvarial defect model enhances local bone formation [13].

Taken together, preclinical data suggest that rhGDF-5 may have a significant potential not only to induce/support periodontal wound healing/regeneration but also to support regeneration elsewhere in the axial and appendicular skeleton [14]. Beyond preclinical studies, controlled clinical pilot studies are needed to demonstrate clinical potential and safety.

However, although rhGDF-5 appears to be promising for enhancing periodontal regeneration, until now, it has not been used in humans to treat periodontal defects and thus, the safety and the clinical potential of the material are unknown. Therefore, an exploratory study was specifically designed to evaluate for the first time in humans the clinical and histological outcomes following treatment of intrabony defects with open flap debridement (OFD) alone or with
OFD and rhGDF- 5 adsorbed onto a particulate $\beta$-tricalcium phosphate $(\beta-\mathrm{TCP})$ carrier.

The aim of this paper is to report on the study protocol, safety profile, the early healing phase and the clinical outcomes at 24 weeks while the histological outcomes are presented and discussed in great detail in a subsequent paper [15].

\section{Materials and methods}

Overall study design and plan

This pilot, phase IIa study used a stratified randomized, open, controlled, two-arm, parallel group design. The overall design and patient treatment allocation is summarized in Fig. 1. The study was conducted at the Department of Periodontology, Semmelweis University, Budapest, Hungary between July 2007 and August 2008. The study protocol was approved by the Hungarian National Institute of Pharmacy and the Institutional Ethics Committee (application no. $32579 / 40 / 06$ ) of the Semmelweis University, Budapest, Hungary (TUKEB (RICSRE) no. 20/2007). All patients received oral and written explanations of the research protocol. Patients signed a consent form providing the possibility of withdrawing from the study at any time. The study was planned and conducted in compliance with the Declaration of Helsinki of 1975 as revised in 2000, Good Clinical Practice, and relevant local laws.

The total study duration was 175-182 days, in all ten visits/patient. After screening, selected patients received flap surgery (control) or flap surgery combined with implantation of rhGDF-5/ $\beta$-TCP at the qualified defect site (Visit 2). They then returned for general and oral health evaluations as well as professional tooth cleanings following a set schedule (Visits 3 through 8). Blood samples were collected at screening (Visit 1), and at weeks 2 and 24 (Visits 3 and 9) to evaluate routine hematology and clinical chemistry, rhGDF-5 plasma levels, and antirhGDF-5 antibody formation.

\section{Study population}

Twenty Caucasian male and female patients, nonsmokers, in good general health, volunteered to participate in this study. They all exhibited advanced chronic periodontitis with one deep intrabony defect located at a maxillary or mandibular single-rooted tooth without root concavities/ furrows or at the mesial or distal aspect of a mandibular molar without contacting teeth (Fig. 2). Mandibular incisors and teeth with furcation involvements were excluded. Only teeth with a probing depth $\geq 6 \mathrm{~mm}$ and an intrabony component $\geq 4 \mathrm{~mm}$ as estimated from long cone parallel 


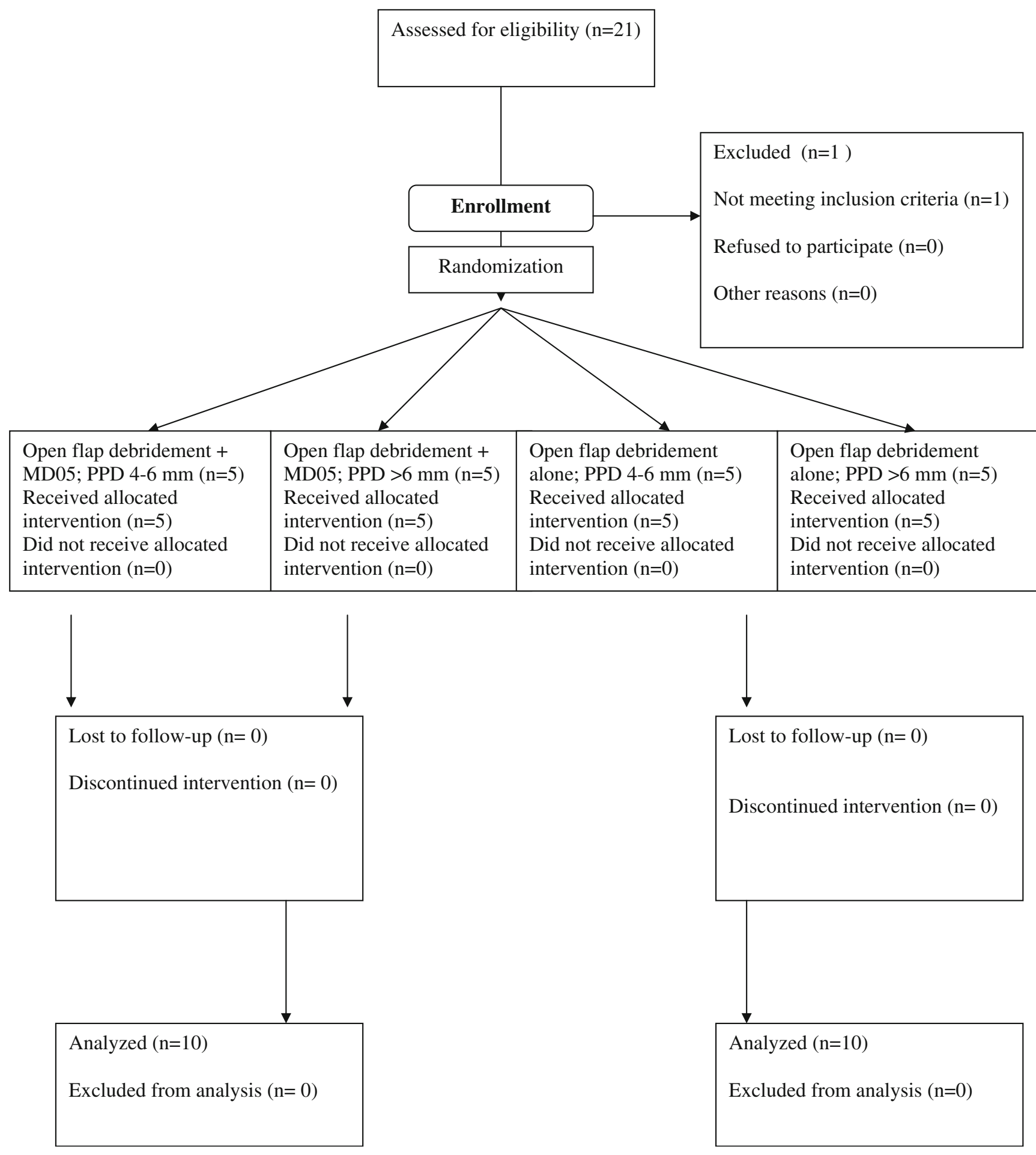

Fig. 1 Patient flow chart/flow of participants through each stage

technique radiographs confirmed during surgery were considered (Fig. 3). Moreover, the patients were expected to meet oral hygiene standards encompassing full mouth plaque and bleeding scores $<20 \%$ after completion of basic periodontal therapy $[16,17]$. Each patient contributed one tooth subject to the study treatment.
Main exclusion criteria were: a) women of childbearing potential (FSH level $<25 \mathrm{IU} / \mathrm{L}$ and menstrual bleeding within 6 months)/pregnant or lactating women; b) tobacco smoking; c) evidence of acute/chronic infection at the study site; d) previous ( $<2$ months)/current treatment with systemic corticosteroids of a prednisone equivalent $>5 \mathrm{mg}$ /day; e) 
Fig. 2 Flap surgery plus rhGDF- $5 / \beta$-TCP: presurgery (a); intrasurgery defect morphology (b); site following implantation of rhGDF-5/ $\beta$-TCP (c); and site at 24 weeks (d)
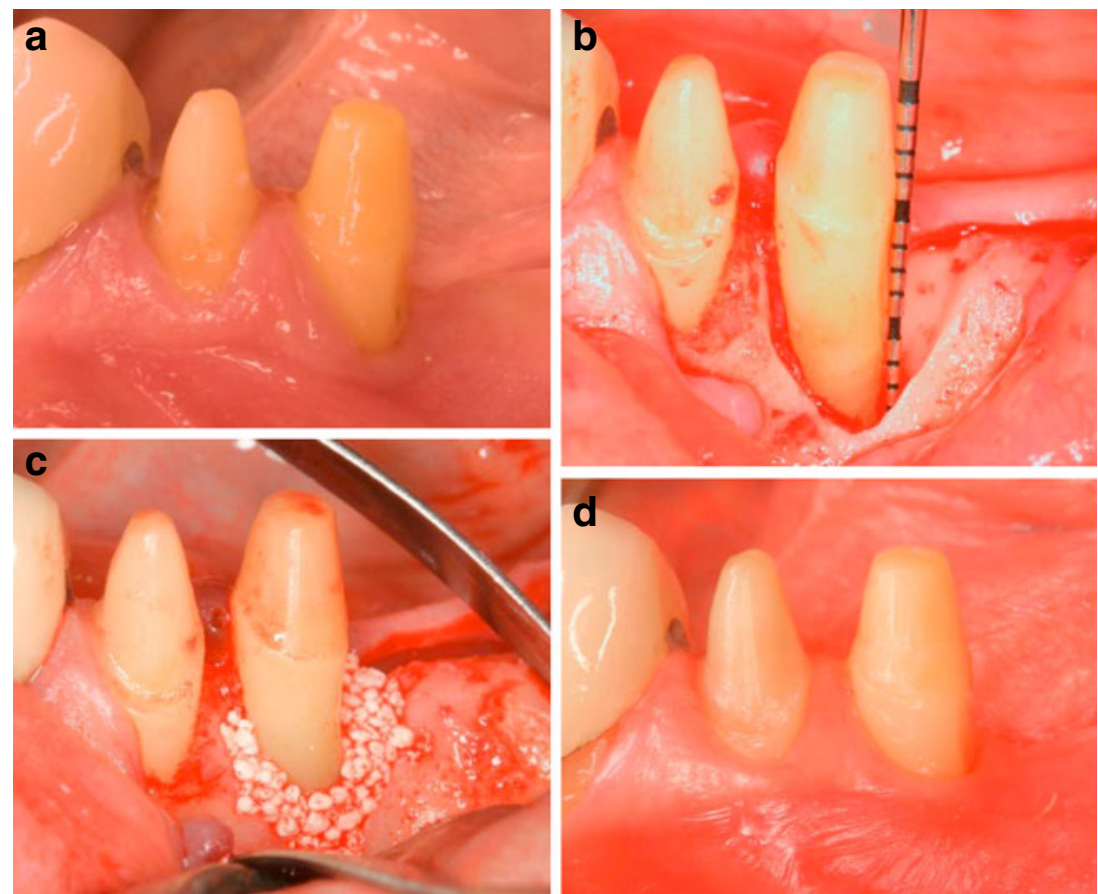

previous ( $<12$ months)/current treatment with drugs influencing bone metabolism including calcitonin, parathormone, bisphosphonates, or fluoride; f) common contraindications for periodontal surgery; and g) clinically relevant cardiovascular, hepatic, and renal diseases. Due to the explorative type of this study, a sample size of ten patients/group was selected.

\section{rhGDF-5/ $\beta-\mathrm{TCP}$}

The rhGDF-5/ $\beta$-TCP device (Scil Technology $\mathrm{GmbH}$, Martinsried, Germany) comprises rhGDF-5 coated onto a synthetic inorganic carrier, $\beta$-TCP, at a concentration of $500 \mu \mathrm{g} / \mathrm{g} \beta$-TCP [13]. The $\beta$-TCP carrier consists of particles of 500 to $1,000 \mu \mathrm{m}$ in size with interconnecting porosity. It comprises microporous and macroporous irreg-

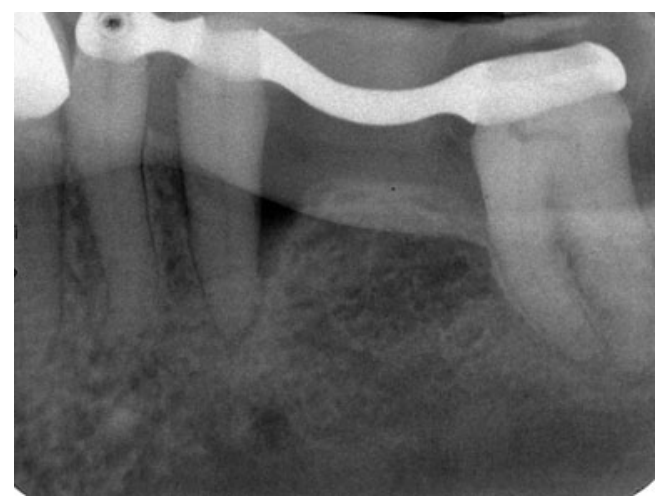

Fig. 3 Preoperative radiograph of the defect depicted in Fig. 2. A deep intrabony defect is visible ular granules of a phase purity $>95 \%$. The results of porosity analysis have shown $43.7 \%$ microporosity, an average pore diameter of $2.12 \mu \mathrm{m}$, and a totale pore area of $0.647 \mathrm{~m}^{2} / \mathrm{g}$. The pore size of the macropores ranges between 100 and $400 \mu \mathrm{m}$. The surface area is estimated at $1.2 \mathrm{~m}^{2} / \mathrm{g}$ [13]. The rhGDF-5 protein was coated onto the carrier using Scil Technology's proprietary technology. One vial rhGDF-5/ $\beta$-TCP contained $250 \mu \mathrm{g}$ rhGDF-5 and $0.5 \mathrm{~g}$ $\beta$-TCP [13]. In vitro analysis of the carrier used in this study has shown that almost the entire amount of rhGDF-5 was released from the carrier within the first 7 days [18].

\section{Randomization and treatment allocation}

Randomization was performed using a computer-generated randomization list via block randomization. Ten patients were randomized to each treatment group. A separate random scheme was generated. The investigators were masked to the block length. The sponsor retained the randomization scheme for control purposes. The investigator implemented the predefined randomization by opening a randomization envelope at the appointment for surgery (Visit 2). The randomization code was opened only after the defect site was fully prepared. The defects were randomly assigned to receive: rhGDF-5/ $\beta$-TCP following the manufacturer's instructions (test), or no additional treatment (control). All randomized patients completed the study. Masking of treatment was not applicable because the test group received $\mathrm{rhGDF}-5 / \beta-\mathrm{TCP}$ whereas the control group was treated by periodontal surgery only without additional treatment. 
Safety assessment

Adverse events were monitored and recorded throughout the study, as well as laboratory values, vital signs, and physical status. Adverse events were coded using the Medical Dictionary of Regulatory Activities (MedDRA) [http://www.meddramsso.com/index.asp]. Summaries and tabulations by severity and relationship to therapy were based on the preferred terms and the primary system organ classes (SOCs). Blood samples were collected at screening (Visit 1), 2 weeks postsurgery (Visit 3), and prior to conclusion of study (Visit 9) to determine laboratory values (clinical chemistry, hematology), rhGDF-5 plasma levels, and antirhGDF-5 antibodies.

The determination of rhGDF-5 in human plasma (EDTA) samples was carried out by Elisa over a quantitation range of $40 \mathrm{pg} / \mathrm{ml}$ to $1,250 \mathrm{pg} / \mathrm{ml}$. A monoclonal antibody specific for rhGDF-5 has been precoated on a 96-well plate. Standards/QCs and samples were then pipetted into the wells and any rhGDF-5 present was bound by the immobilized antibody. After washing away any unbound substances, a biotinylated monoclonal antibody specific for rhGDF-5 was added to the wells. After a second washing step, PolyHRP Streptavidin was added that bound to the biotinylated antibody. After a third washing step, peroxidase bound in the complex was visualized by TMB $\left(3,3^{\prime}, 5,5^{\prime}\right.$-Tetramethylbenzidine) substrate solution. After stopping the enzymatic reaction with sulfuric acid, the intensity of the resulting color was determined at $450 \mathrm{~nm}$. The color intensity was proportional to the concentration of rhGDF-5 in the sample.

\section{Clinical assessment}

Clinical outcomes were evaluated at baseline and at 24 weeks postsurgery. Probing depth (PD), gingival recession (GR) and clinical attachment level (CAL) were recorded using a standard periodontal probe (UNC 15, Hu-Friedy, Chicago, IL, USA). Intraoral radiographs were taken with the long cone parallel technique at baseline and at 24 weeks postsurgery (Figs. 3 and 4). However, due to the design of the study (i.e. no grafting in the control group), the radiographs were not evaluated for hard tissue changes.

Full mouth plaque and bleeding scores were recorded as a percentage of total surfaces (four surfaces/tooth) with the presence of plaque/bleeding on probing, respectively [16, 17]. One calibrated examiner, masked to the patients' treatment protocol, performed all clinical recordings.

\section{Pretreatment procedures}

All patients had completed basic periodontal therapy (individual oral hygiene instructions, supra- and subgingi-



Fig. 4 Postoperative radiograph of the defect depicted in Fig. 2 demonstrating defect fill at 24 weeks following surgery

val scaling and root planing) 8 weeks before screening. If necessary, composite splinting of mobile teeth or eventually fixed temporary restorations were completed.

\section{Periodontal surgery}

One experienced periodontist (PW) performed all surgeries using local anesthesia, microsurgical instrumentation, and appropriate magnification (Fig. 2). The surgical technique was exactly the same for both the test and control groups. An intracrevicular incision was made on the buccal and lingual aspects of the surgical site. The flap was horizontally extended to accommodate the defect location and configuration, and ensured tension-free wound closure for primary intention healing. Vertical releasing incisions were not used. Granulation tissue removal and root instrumentation followed elevation of the mucoperiosteal flaps. In the test group, six patients received one-half vial rhGDF- $5 / \beta-\mathrm{TCP}$, one patient received three-fourth vial $\mathrm{rhGDF}-5 / \beta-\mathrm{TCP}$, and three patients received one vial rhGDF-5/ $\beta$-TCP (one vial rhGDF-5/ $\beta$-TCP contains $250 \mu \mathrm{g}$ rhGDF-5 and $0.5 \mathrm{~g} \beta$-TCP).

The mucoperiosteal flaps were then adapted and closed using vertical or horizontal holding mattress sutures and interrupted closing monofilament sutures (5/0 Dafilon; B. Braun Melsungen AG, Melsungen Germany).

\section{Postsurgical protocol}

Postsurgery care included pain control (Nurofen, $200 \mathrm{mg}$, 3-4 times per day, Reckitt Benckiser, Slough, UK), systemic (Augmentin $625 \mathrm{mg}$, GlaxoSmithKline, London, UK London, UK; TID/7 days) and local (twice daily $0.2 \%$ chlorhexidine; Curasept, Curadent International AG, Kriens, Switzerland; rinses for $1 \mathrm{~min}, \mathrm{BID} / 4$ weeks) antimicrobial control. Antibiotic therapy started immediately after surgery. 
Sutures were removed at day 14. A series of control and recall appointments were scheduled (biweekly, the first 6 weeks and then monthly until the end of the study) including reinforcements of oral hygiene and professional supragingival tooth cleaning.

\section{Statistical analysis}

The statistical analysis was conducted on an intent-to-treat basis. All randomized patients with periodontal treatment were included in the intent-to-treat population. Paired sample $t$-test and Wilcoxon signed-rank test were used to evaluate the impact of surgical interventions on the various clinical parameters. Mann-Whitney $U$ test (rank sum test) was used to analyze differences among the various outcome variables between treatment groups. No formal statistical comparisons were made related to safety data.

\section{Results}

\section{Patient demographics}

Twenty-one patients were screened, 20 patients fulfilling the inclusion criteria were randomized into two groups of ten patients each (Fig. 1). One female patient was not enrolled due to a low FSH level. Sixteen patients were male and four, female. One female patient was randomized to the control group and three to the $\operatorname{rhGDF}-5 / \beta-\mathrm{TCP}$ group. All four female patients were postmenopausal. Patient mean age was $48.8 \pm 10.6$ years (range $33-$ 74 years). Age did not differ considerably between treatment groups; median age was 50.0 years for both groups. No dropouts occurred; all randomized patients completed the study. The depth of the intrabony component measured $6.7 \pm 2.8 \mathrm{~mm}$ in the test and $6.4 \pm 2.1 \mathrm{~mm}$ in the control group, respectively (Tables 1 and 2).

\section{Protocol deviations}

A few patient visits occurred out of schedule. Blood collection Visit 9 was completed 1-5 days early in five patients. The biopsy procedure was performed 1-6 days early or 1-3 days late in seven patients. Two patients showed increased liver enzyme values at screening (ALT $=$ $123 \mathrm{U} / \mathrm{L}, \mathrm{AST}=107 \mathrm{U} / \mathrm{L}, \mathrm{GGT}=142 \mathrm{U} / \mathrm{L}$ and $\mathrm{ALT}=101 \mathrm{U} / \mathrm{L}$, $\mathrm{GGT}=382 \mathrm{U} / \mathrm{L}$ ) that decreased to normal range within 2 weeks (Visit 3) except GGT. No chronic liver disorder was reported for either patient. One patient had insulin independent diabetes $(\mathrm{Hb} 1 \mathrm{Ac}=10.3 \%$ at screening $)$, which was medically controlled. None of these protocol deviations was considered as major violation, and therefore, all patients were included in the analyses.

\section{Clinical characteristics}

Full mouth plaque scores at Visit 2 averaged $7.3 \pm 6.7 \%$ for the $\mathrm{rhGDF}-5 / \beta-\mathrm{TCP}$ and $8.9 \pm 4.8 \%$ for the control group; and full mouth bleeding scores $11.2 \pm 4.1 \%$ for the rhGDF$5 / \beta$-TCP and $12.7 \pm 5.4 \%$ for the control group. Probing depths averaged $9.1 \pm 1.3 \mathrm{~mm}$ for the rhGDF-5/ $\beta$-TCP and $9.2 \pm 2.3 \mathrm{~mm}$ for the control group. Clinical attachment level averaged $12.2 \pm 1.5 \mathrm{~mm}$ for the rhGDF-5/ $\beta-\mathrm{TCP}$ and $11.4 \pm$ $3.5 \mathrm{~mm}$ for the control group.

The depth of the intrabony component as measured during surgery measured $6.7 \pm 2.8 \mathrm{~mm}$ for the $\mathrm{rhGDF}-5 / \beta$ TCP and $6.4 \pm 2.1 \mathrm{~mm}$ for the control group. The defects displayed predominantly one- and two-wall configurations (Tables 1 and 2).

\section{Safety findings}

The safety profile was comparable for patients receiving rhGDF-5/ $\beta$-TCP and control treatments. All abnormal hematology and clinical chemistry values were judged as clinically nonrelevant. Most common abnormal values were GGT, followed by cholesterol, glucose, and white blood cell count. Summary statistics did not show remarkable trends from Visits 1 to 9 for any of the parameters analyzed. All patients showed negative antirhGDF-5 antibody levels at screening and Visits 3 and 9. No relevant rhGDF-5 plasma levels were detected in any patient. Two patients, both belonging to the rhGDF-5/ $\beta$-TCP group showed rhGDF-5 plasma levels at screening (Visit 1 ) and postsurgery (Visits 3 and 9). One patient showed a plasma level of $46.7 \mathrm{pg} / \mathrm{mL}$ rhGDF- 5 at baseline (before implantation of rhGDF-5/ $\beta$ TCP) vs. $47.3 \mathrm{pg} / \mathrm{mL}$ at Visit 3, and $57.9 \mathrm{pg} / \mathrm{mL}$ at Visit 9 . The other patient showed a plasma level of $514 \mathrm{pg} / \mathrm{mL}$ rhGDF-5 at baseline vs. $427 \mathrm{pg} / \mathrm{mL}$ at Visit 3, and $690 \mathrm{pg} / \mathrm{mL}$ at Visit 9. Due to the fact that the measured rhGDF-5 plasma levels were already positive at the baseline (before periodontal surgery) and did not increase throughout the study, a causal relationship to study medication can be excluded. For all other samples, rhGDF-5 plasma levels were below the limit of quantification $(<40.0 \mathrm{pg} / \mathrm{mL})$. It may, thus, be anticipated that these results were false positive.

\section{Adverse events}

The overview of the adverse events is summarized in Table 3. All adverse events were judged as mild or moderate. Seventy-two events were reported; 54 in seven patients from the rhGDF-5/ $\beta$-TCP group ( 42 of which for one single patient), and 18 in eight patients from the control. As these were always single isolated events, one adverse event was recorded for each episode. Most events 
Table 1 Patients, experimental teeth and surfaces, predominant defect morphology, intrasurgery defect depth, initial pocket probing depth (PD), clinical attachment level (CAL) and gingival recession (GR), and changes in primary outcome variables $(\mathrm{mm})$ for defect sites receiving flap surgery combined with $\mathrm{rhGDF}-5 / \beta-\mathrm{TCP}$

\begin{tabular}{|c|c|c|c|c|c|c|c|c|c|}
\hline Patient & Tooth & Defect morphology & Defect depth & $\mathrm{PD}$ & CAL & GR & $\Delta \mathrm{PD}$ & $\triangle \mathrm{CAL}$ & $\Delta \mathrm{GR}$ \\
\hline 2 & $35 \mathrm{~d}$ & 1-Wall & 7 & 8 & 12 & 4 & 5 & 5 & 0 \\
\hline 3 & $36 \mathrm{~d}$ & 2-Wall & 5 & 9 & 13 & 4 & 4 & 4 & 0 \\
\hline 6 & $11 \mathrm{~m}$ & 2-Wall & 4 & 9 & 12 & 3 & 3 & 4 & 1 \\
\hline 10 & $34 \mathrm{~d}$ & Circumferential & 5 & 9 & 11 & 2 & 4 & 3 & -1 \\
\hline 13 & $23 p$ & 1-Wall & 11 & 11 & 15 & 4 & 6 & 6 & 0 \\
\hline 14 & $23 \mathrm{~d}$ & 2-Wall & 11 & 11 & 12 & 1 & 4 & 3 & -1 \\
\hline 16 & $21 \mathrm{~m}$ & 1-Wall & 7 & 10 & 12 & 2 & 3 & 2 & -1 \\
\hline 17 & $21 \mathrm{~m}$ & 1-Wall & 4 & 7 & 10 & 3 & 2 & 0 & -2 \\
\hline 18 & $12 \mathrm{~d}$ & 1-Wall & 4 & 8 & 11 & 3 & 3 & 2 & -1 \\
\hline 19 & $45 \mathrm{~d}$ & Circumferential & 9 & 9 & 14 & 5 & 3 & 3 & 0 \\
\hline Mean \pm SD & & & $6.7 \pm 2.8$ & $9.1 \pm 1.3$ & $12.2 \pm 1.5$ & $3.1 \pm .2$ & $3.7 \pm 1.2$ & $3.2 \pm 1.7$ & $0.5 \pm 0.8$ \\
\hline
\end{tabular}

were related to back pain (14 events) and headache (26 events). The following two events, in two different patients, were judged to be possibly related to the regenerative surgery but not necessarily related to the rhGDF-5: delayed epithelialization and secondary healing of the interdental papilla. Both were judged as mild and the patients recovered without sequelae. No withdrawals due to an adverse event were recorded. There were also no meaningful changes in vital signs that would raise a safety concern.

Early wound healing events

Healing following surgeries progressed without major complications. Primary intention healing was observed in nine of ten patients in the rhGDF-5/ $\beta$-TCP group, and in all ten patients in the control group. One patient in the rhGDF$5 / \beta$-TCP group experienced a slightly delayed epithelial- ization of the interdental papilla resulting in complete wound closure within 3 weeks.

\section{Clinical outcomes}

At 6 months, both treatments resulted in significant improvements in terms of $\mathrm{PD}$ reduction and $\mathrm{CAL}$ gain compared to baseline. Treatment with rhGDF-5/ $\beta$-TCP resulted in higher, but statistically not significant, $\mathrm{PD}$ reduction $(3.7 \pm 1.2$ vs. $3.1 \pm 1.8 \mathrm{~mm} ; p=0.26)$ and CAL gain $(3.2 \pm 1.7$ vs. $1.7 \pm$ $2.2 \mathrm{~mm} ; p=0.14$ ) compared to the control (Tables 1 and 2).

\section{Discussion}

This pilot randomized, controlled study is the first to investigate the influence of GDF-5 on periodontal wound
Table 2 Patients, experimental teeth and surfaces, predominant defect morphology, intrasurgery defect depth, initial pocket probing depth (PD), clinical attachment level (CAL) and gingival recession (GR), and changes in primary outcome variables $(\mathrm{mm})$ for defect sites receiving flap surgery alone (control)

\begin{tabular}{|c|c|c|c|c|c|c|c|c|c|}
\hline Patient & Tooth & Defect morphology & Defect depth & PD & CAL & GR & $\Delta \mathrm{PD}$ & $\triangle \mathrm{CAL}$ & $\Delta \mathrm{GR}$ \\
\hline 1 & $21 \mathrm{~m}$ & Circumferential & 4 & 9 & 10 & 1 & 2 & 1 & -1 \\
\hline 4 & $12 \mathrm{~m}$ & 2-Wall & 7 & 9 & 11 & 2 & 4 & 4 & 0 \\
\hline 7 & $11 \mathrm{~m}$ & 1-Wall & 7 & 12 & 13 & 1 & 6 & 4 & -2 \\
\hline 8 & $23 \mathrm{~m}$ & 1-Wall & 5 & 8 & 9 & 1 & 3 & 1 & -2 \\
\hline 9 & $22 \mathrm{~m}$ & 1-Wall & 5 & 8 & 10 & 2 & 3 & 0 & -3 \\
\hline 11 & $35 \mathrm{~d}$ & 2-Wall & 5 & 7 & 8 & 1 & 1 & -1 & -2 \\
\hline 12 & $44 d$ & 2-Wall & 9 & 13 & 17 & 4 & 6 & 5 & -1 \\
\hline 15 & $34 d$ & 1-Wall & 9 & 8 & 15 & 7 & 3 & 3 & 0 \\
\hline 20 & $35 \mathrm{~d}$ & Circumferential & 9 & 12 & 15 & 3 & 2 & 1 & -1 \\
\hline 21 & $11 \mathrm{~m}$ & 1-Wall & 4 & 6 & 6 & 0 & 1 & -1 & -2 \\
\hline Mean \pm SD & & & $6.4 \pm 2.1$ & $9.2 \pm 2.3$ & $11.4 \pm 3.5$ & $2.2 \pm 2.0$ & $3.1 \pm 1.8$ & $1.7 \pm 2.2$ & $1.4 \pm 1.0$ \\
\hline
\end{tabular}


Table 3 Overview of adverse events (AEs). No serious adverse events occurred

\begin{tabular}{lll}
\hline & rhGDF-5/ß-TCP & Control \\
\hline $\begin{array}{l}\text { Number of patients with AEs, and number (AEs) } \\
\text { Number of patients with AEs possibly related to study medication, and number (AEs) }\end{array}$ & $7(54)$ & $2(2)$ \\
\hline
\end{tabular}

healing/regeneration in humans. An important finding was that no safety concerns related to $\mathrm{rhGDF}-5 / \beta-\mathrm{TCP}$ were encountered. Minor adverse events appeared to be rather related to the surgical intervention than to the used regenerative material, which did not seem to have any negative influence upon the clinical outcomes. None of the patients exhibited antiGDF-5 antibody levels while elevated GDF-5 plasma levels were observed in two patients receiving rhGDF-5/ $\beta$-TCP. Overall laboratory evaluations failed to show any differences in the safety profiles between the experimental and control groups indicating that the rhGDF-5 formulation appears safe.

Full mouth plaque and bleeding scores were maintained below $20 \%$ throughout the study, indicating an optimal level of infection control. The observation that healing was uneventful in both groups also indicates that the rhGDF-5/ $\beta$-TCP treatment was well tolerated and did not elicit any local adverse reactions. In the test group, special attention was paid not to overfill the defects to avoid undue flap tension during wound closure. Wound closure for primary intention healing was maintained in all but one defect receiving rhGDF-5/ $\beta$-TCP showing slightly delayed epithelization of the interdental papilla. Taken together, these clinical observations suggest that the rhGDF-5/ $\beta$-TCP construct did not appear to exert any detrimental influence on periodontal wound healing/regeneration.

The clinical evaluation has indicated that both, open flap debridement (OFD) combined with rhGDF-5/ $\beta$-TCP and OFD alone may result in statistically significant probing depth reductions and clinical attachment gains compared to baseline. Application of $\operatorname{rhGDF-5/\beta -TCP}$ however, resulted in greater, although statistically not significant, probing depth reduction and clinical attachment gain compared to the control. These findings are in agreement with those reported in previous preclinical studies indicating a beneficial effect of GDF-5 on periodontal wound healing/regeneration $[10,11,19]$. On the other hand, the magnitude of clinical improvements appeared to be in the range of those obtained with other regenerative materials such as a recombinant plateletderived growth factor (rhPDGF BB) on a $\beta$-TCP carrier, an enamel matrix protein derivative alone or guided tissue regeneration either alone or combined with grafting materials [20-27]. Furthermore, it is also important to note that the results observed in the control group compare favorably with previous studies evaluating treatment of intrabony defects using flap surgery alone indicating that substantial clinical improvements may be achieved with this treatment modality if an optimal level of plaque control is maintained [21-23, 26-28].

Another important issue, which should to be carefully considered, is the interpretation of the findings. First of all, due to its exploratory nature, the study does not have an adequate statistical power to detect possible differences between the groups. Secondly, a third treatment group including the use of $\beta$-TCP alone would have been needed to evaluate the possible influence of the carrier on the clinical outomes. At this point, it needs to be emphasized that the biological rationale of using $\beta$-TCP alone for obtaining periodontal regeneration is questionable since findings from human histological studies have failed to demonstrate periodontal regeneration following filling of intrabony defects with $\beta$-TCP [29]. Therefore, $\beta$-TCP-based materials are not recommended to be used alone, but mainly as carriers for biologically active molecules such as the growth factors used in the present study. On the other hand, it should be kept in mind that the present study was not only designed to evaluate the safety of rhGDF-5/ $\beta$-TCP but also the histological outcomes [15]. The histological evaluation has indicated that treatment with OFD + rhGDF-5/ $\beta$-TCP resuted in 2 - to 3 -fold higher amount of new bone and new cementum formation compared to OFD alone without differences in frequency of root resorption and ankylosis between the two groups [15]. The amount of residual $\beta$-TCP carrier juxtaposed to the root surface in the present group of biopsies was generally small (mean $8.4 \%$ ), suggesting that this carrier would completely degrade and/or resorb within a relatively short interval [30]. In conclusion, the present findings indicate that in the tested concentration the use of $\operatorname{rhGDF-5/\beta -TCP}$ appeared to be safe and the material possesses a sound biological rationale. Thus, further, adequately powered, randomized controlled clinical trials are warranted to confirm the clinical relevance of this new approach in regenerative periodontal therapy. 
Sources of funding This study was supported by a grant from Scil Technology GmbH, Martinsried, Germany.

Conflict of interest statement Dr. Capsius is an employee of Scil Technology GmbH, Martinsried, Germany. Dr. Wikesjö is a consultant to Scil Technology GmbH. Drs. Sculean and Stavropulos received a grant from Scil Technology GmbH to conduct this study. Drs. Windisch, Molnár, Szendröi-Kiss, Szilágyi, Rosta, and Horváth report no finacial or other conflicting relationship to any products involved in this study.

\section{References}

1. Caton JG (2000) Greenstein GG (1993) Factors related to periodontal regeneration. Periodontol 1:9-15

2. Wikesjö UME (2000) Selvig KA (1999) Periodontal wound healing and regeneration. Periodontol 19:21-39

3. Polimeni G, Xiropaidis AV (2000) Wikesjö UME (2006) Biology and principles of periodontal wound healing/regeneration. Periodontol 41:30-47

4. World Workshop in Periodontology (1996) The American Academy of Periodontology. Ann Periodontol 1:618-670

5. Morotome Y, Goseki-Sone M, Ishikawa I, Oida S (1998) Gene expression of growth and differentiation factors-5, -6 , and -7 in developing bovine tooth at the root forming stage. Biochem Biophys Res Commun 244:85-90

6. Sena K, Morotome Y, Baba O, Terashima T, Takano Y, Ishikawa I (2003) Gene expression of growth differentiation factors in the developing periodontium of rat molars. J Dent Res 82:166-171

7. Spiro RC, Liu L, Heidaran MA, Thompson AY, Ng CK, Pohl J, Poser JW (2000) Inductive activity of recombinant human growth and differentiation factor-5. Biochem Soc Trans 28:362-368

8. Nakamura T, Yamamoto M, Tamura M, Izumi Y (2003) Effects of growth/differentiation factor-5 on human periodontal ligament cells. J Periodont Res 38:597-605

9. Wikesjö UME, Sorensen RG, Kinoshita A, Li XJ, Wozney JM (2004) Periodontal repair in dogs: effect of recombinant human bone morphogenetic protein-12 (rhBMP-12) on regeneration of alveolar bone and periodontal attachment. A pilot study. J Clin Periodontol 31:622-670

10. Kim TG, Wikesjö UME, Cho KS, Chai JK, Pippig SD, Siedler M, Kim CK (2009) Periodontal wound healing/regeneration following application of recombinant human growth/differentiation factor-5 (rhGDF5 ) in an absorbable collagen sponge carrier into one-wall intrabony defects in dogs. A dose range study. J Clin Periodontol 36:589-597

11. Lee JS, Wikesjö UME, Jung UW, Choi SH, Pippig S, Siedler M, Kim CK (2010) Periodontal wound healing/regeneration following implantation of recombinant human growth/differentiation factor-5 in a beta-tricalcium phosphate carrier into one-wall intrabony defects in dogs. J Clin Periodontol 37:382-389

12. Galois L, Mainard D, DeLagoutte JP (2002) Beta-tricalcium phosphate ceramic as a bone substitute in orthopaedic surgery. Int Orthop 26:109-115

13. Pöhling S, Pippig SD, Hellerbrand K, Siedler M, Schütz A, Dony C (2006) Superior effect of MD05, beta-tricalcium phosphate coated with recombinant human growth/differentiation factor-5, compared to conventional bone substitutes in the rat calvarial defect model. J Periodontol 77:1582-1590

14. Moore Y, Dickinson DP, Wikesjö UME (2010) Growth/differentiation factor-5 (GDF-5): a candidate therapeutic agent for periodontal regeneration? Review of preclinical data. J Clin Periodontol 37:288-298
15. Stavropoulos A, Windisch P, Gera I, Sculean A, Capsius B, Wikesjö UME (2011) A phase IIa randomized controlled clinical and histological pilot study evaluating rhGDF-5/ $\beta$-TCP for periodontal regeneration. J Clin Periodontol (accepted for publication)

16. O'Leary TJ, Drake RB, Naylor JE (1972) The plaque control record. J Clin Periodontol 43:38

17. Ainamo J, Bay I (1975) Problems and proposals for recording gingivitis and plaque. Int Dent J 25:229-235

18. Pöhling S, Jochims K, Happersberger P, Hellerbrand K, Bolz W, Kohnert U (2002) Enhancement of bone growth by coating of osteoinductive beta-tricalcium phosphate (beta- TCP) with recombinant human growth factor-5 (rhGDF-5). 2nd European Conference on Bone Morphogenetic Proteins, May 2002, Zagreb.

19. Kwon DH, Bennett W, Herberg S, Bastone P, Pippig S, Rodriguez NA, Susin C, Wikesjö UME (2010) Evaluation of an injectable rhGDF-5/PLGA composite for minimally invasive periodontal regenerative procedures: a histological study in the dog. J Clin Periodontol 37:390-397

20. Nevins M, Giannobile WV, McGuire MK, Kao RT, Mellonig JT, Hinrinchs JE, McAllister BS, Murphy KS, McClain PK, Nevins ML, Paquette DW, Han TJ, Reddy MS, Lavin PT, Genco RJ, Lynch SE (2005) Platelet-derived growth factor stimulates bone fill and rate of attachment level gain: results of a large multicenter randomized controlled trial. J Periodontol 76:2205-2215

21. Pontoriero R, Wennström J, Lindhe J (1999) The use of barrier membranes and enamel matrix proteins in the treatment of angular bone defects. A prospective controlled clinical study. J Clin Periodontol 26:833-840

22. Sculean A, Windisch P, Chiantella GC, Donos N, Brecx M, Reich E (2001) Treatment of intrabony defects with enamel matrix proteins and guided tissue regeneration. A prospective controlled clinical study. J Clin Periodontol 28:397-403

23. Tonetti MS, Lang NP, Cortellini P, Suvan JE, Adriaens P, Dubravec D, Fonzar A, Fourmousis I, Mayfield L, Rossi R, Silvestri M, Tiedemann C, Topoll H, Vangsted T, Wallkamm B (2002) Enamel matrix proteins in the regenerative therapy of deep intrabony defects. A multicentre randomized controlled clinical trial. J Clin Periodontol 29:317-325

24. Kuru B, Yilmaz S, Argin K, Noyan U (2006) Enamel matrix derivative alone or in combination with a bioactive glass in wide intrabony defects. Clin Oral Invest 10:227-234

25. Yilmaz S, Cakar G, Yildirim B, Sculean A (2010) Healing of two and three wall intrabony periodontal defects following treatment with an enamel matrix derivative combined with autoneous bone. J Clin Periodontol 37:544-550

26. Sculean A, Berakdar M, Chiantella GC, Donos N, Arweiler NB, Brecx M (2003) Healing of intrabony defects following treatment with a bovine derived xenograft and collagen membrane. A controlled clinical study. J Clin Periodontol 30:73-80

27. Tonetti MS, Cortellini P, Lang NP, Suvan JE, Adriaens P, Dubravec D, Fonzar A, Fourmousis I, Rasperini G, Rossi R, Silvestri M, Topoll H, Wallkamm B, Zybutz M (2004) Clinical outcomes following treatment of human intrabony defects with GTR/bone replacement material or access flap alone. A multicenter randomized controlled clinical trial. J Clin Periodontol 31:770-776

28. Rosling B, Nyman S, Lindhe J (1976) The effect oy systemic plaque control on bone regeneration in infrabony pockets. J Clin Periodontol 3:38-53

29. Stavropoulos A, Windisch P, Szendröi-Kiss D, Rosta P, Gera I, Sculean A (2010) Clinical and histological evaluation of granular beta tricalcium phosphate for the treatment of human intrabony periodontal defects: a report on five cases. J Periodontol 81:325-334

30. LeGeros RZ (1993) Biodegradation and bioresorption of calcium phosphate ceramics. Clin Mater 14:65-88 